\title{
LIM-Homeobox Gene Lhx5 Is Required for Normal Development of Cajal-Retzius Cells
}

\author{
Amaya Miquelajáuregui, ${ }^{1}$ Alfredo Varela-Echavarría, ${ }^{1}$ M. Laura Ceci, ${ }^{2}$ Fernando García-Moreno, ${ }^{2}$ Itzel Ricaño, ${ }^{1}$ \\ Kimmi Hoang, ${ }^{3}$ Daniela Frade-Pérez, ${ }^{1}$ Carlos Portera-Cailliau, ${ }^{4}$ Elisa Tamariz, ${ }^{1}$ Juan A. De Carlos, ${ }^{2}$ Heiner Westphal, ${ }^{3}$ \\ and Yangu $\mathrm{Zhao}^{3}$ \\ ${ }^{1}$ Instituto de Neurobiología, Universidad Nacional Autónoma de México, Querétaro, Querétaro 76230, Mexico, ${ }^{2}$ Instituto Cajal (Consejo Superior de \\ Investigaciones Científicas), 28002 Madrid, Spain, ${ }^{3}$ Laboratory of Mammalian Genes and Development, Program in Genomics of Differentiation, Eunice \\ Kennedy Shriver National Institute of Child Health and Human Development, National Institutes of Health, Bethesda, Maryland 20892, and ${ }^{4}$ Department of \\ Neurology, David Geffen School of Medicine, University of California, Los Angeles, Los Angeles, California 90095
}

Cajal-Retzius (C-R) cells play important roles in the lamination of the mammalian cortex via reelin secretion. The genetic mechanisms underlying the development of these neurons have just begun to be unraveled. Here, we show that two closely related LIM-homeobox genes $L h x 1$ and $L h x 5$ are expressed in reelin ${ }^{+}$cells in various regions in the mouse telencephalon at or adjacent to sites where the C-R cells are generated, including the cortical hem, the mantle region of the septal/retrobulbar area, and the ventral pallium. Whereas $L h x 5$ is expressed in all of these reelin-expressing domains, $L h x l$ is preferentially expressed in the septal area and in a continuous domain spanning from lateral olfactory region to caudomedial territories. Genetic ablation of $L h x 5$ results in decreased reelin ${ }^{+}$and $p 73^{+}$cells in the neocortical anlage, in the cortical hem, and in the septal, olfactory, and caudomedial telencephalic regions. The overall reduction in number of C-R cells in Lhx5 mutants is accompanied by formation of ectopic reelin ${ }^{+}$cell clusters at the caudal telencephalon. Based on differential expression of molecular markers and by fluorescent cell tracing in cultured embryos, we located the origin of reelin ${ }^{+}$ectopic cell clusters at the caudomedial telencephalic region. We also confirmed the existence of a normal migration stream of reelin ${ }^{+}$cells from the caudomedial area to telencephalic olfactory territories in wild-type embryos. These results reveal a complex role for $L h x 5$ in regulating the development and normal distribution of C-R cells in the developing forebrain.

\section{Introduction}

Cajal-Retzius (C-R) cells, which constitute one of the earliest neuronal cell types in the mammalian telencephalon, are involved in the establishment of the cortical laminar organization by providing the secreted glycoprotein reelin. Loss of reelin function prevents preplate splitting and alters radial migration of cortical plate neurons (for review, see Soriano and Del Río, 2005).

\footnotetext{
Received 0ct. 21, 2009; revised June 14, 2010; accepted June 19, 2010.
}

This work was supported by funds from the intramural research program of National Institute of Child Health and Human Development-National Institutes of Health (NIH), The Wellcome Trust (GR071174AIA), Agencia Española de Cooperación Internacional (A/010585/07), BFU2007-60351/BFI from Spanish Ministerio de Ciencia e Innovación, and Mexican Consejo Nacional de Ciencia y Tecnología (CONACYT) (40286M). A.M. was supported by a fellowship from Dirección General de Asuntos del Personal Académico-Universidad Nacional Autónoma de México, D.F.-P. by a fellowship from CONACYT, F.G.-M. by a postdoctoral contract from the Comunidad Autónoma de Madrid-OLFACTOSENSE Consortium P-SEM-0255-2006, and M.L.C. by a Spanish predoctoral I3P fellowship. Part of this research was performed at the laboratory of Heiner Westphal at the National Institute of Child Health and Human Development-NIH (Bethesda, MD), by A.V.-E. with the support of a National Research Council Associateship Award. Technical support was provided by Anaid Antaramián, Adriana González, Pilar Galarza, Martín García, Cristina González, Nydia Hernández, Alberto Lara, and Omar González. $L h x t^{t z /+}$ founder mice were kindly donated by Tom Jessell. We thank Tom Curran, Antonello Mallamaci, and Magdalena Götz for providing probes and Richard Behringer for the rabbit Lhx1 antibody.

Correspondence should be addressed to either of the following: Dr. Alfredo Varela-Echavarría, Instituto de Neurobiología, Universidad Nacional Autónoma de México, Campus Juriquilla, Querétaro, Querétaro 76230, Mexico, E-mail: avarela@unam.mx; or Dr. Yangu Zhao, Laboratory of Mammalian Genes and Development, Program in Genomics of Differentiation, Eunice Kennedy Shriver National Institute of Child Health and Human Development, National Institutes of Health, Bethesda, MD 20892, E-mail: yzhao@helix.nih.gov.

DOI:10.1523/JNEUROSCI.5563-09.2010

Copyright $\odot 2010$ the authors $\quad 0270-6474 / 10 / 3010551-12 \$ 15.00 / 0$
Several findings have revealed the cortical hem as the main source of C-R cells, and additional sites for their generation have been shown at the septal/retrobulbar area and near the pallial-subpallial boundary (PSB) at the ventral pallium (VP) (Meyer et al., 1998; Takiguchi-Hayashi et al., 2004; Bielle et al., 2005; Yoshida et al., 2006; García-Moreno et al., 2007; Hanashima et al., 2007; Imayoshi et al., 2008; Inoue et al., 2008). More recently, origin sites at the thalamic eminence have also been proposed (Tissir et al., 2009; Abellan et al., 2010). C-R cells migrate tangentially to populate the dorsal telencephalon, but issues regarding their precise site of origin, migratory routes, and relative contribution of each of the different subpopulations are still controversial.

A number of transcription factors and nuclear proteins have been implicated in the control of C-R cell differentiation, migration, or survival. Early observations pointed to a role of genes such as Tbr1, Pax6, Emx1, and Emx2 (Mallamaci et al., 2000; Hevner et al., 2001; Muzio and Mallamaci, 2003; Stoykova et al., 2003). The transcription factor Foxg1 represses the neocortical reelin ${ }^{+}$cell fate in vivo (Hanashima et al., 2004; Muzio and Mallamaci, 2005) and in vitro (Shen et al., 2006; Hanashima et al., 2007). Factors related to particular reelin-expressing cell subpopulations have recently been identified: $p 73$ (Meyer et al., 2002), p21 (Siegenthaler and Miller, 2008), and Zic1-3 (Inoue et al., 2008) for septal- and hem-derived cells, Er81 for septal-derived cells (Zimmer et al., 2010), and Ebf2 for cells of VP origin (Hanashima et al., 2007). A microarray analysis designed to uncover the molecular determinants of $\mathrm{C}-\mathrm{R}$ cell differentiation re- 
vealed a number of genes enriched in the transcriptome of mouse C-R cells (Yamazaki et al., 2004). Among them, known markers of C-R cells such as reelin, calretinin, and p73, and the LIM homeobox genes $L h x 1$ and $L h x 5$ were found to be highly upregulated. $L h x 1$ and Lh $x 5$ were recently confirmed to be expressed in C-R cells in chick, mouse, and macaque (Abellan et al., 2010).

In this study, we analyzed the role of $L h x 1$ and $L h x 5$ in C-R cell development. We found that both $L h x 1$ and $L h x 5$ are expressed in the septum and in a continuous domain that spans the olfactory cortex territory and the caudomedial region adjacent to the diencephalon. Moreover, early $L h x 5$ expression was found in midline structures including the cortical hem. Deletion of $L h \times 5$ caused an overall reduction of $\mathrm{C}-\mathrm{R}$ cell density throughout the developing cortex and the appearance of reelin ${ }^{+}$ectopic cell clusters at the caudal end of the telencephalic vesicle. These results thus reveal a complex role for $L h x 5$ and additionally suggest an early role for Lhxl in C-R cell development.

\section{Materials and Methods}

Animals. Mouse lines maintained in a CD-1 background and carrying the following transgenic alleles were used: $\operatorname{Lh} \times 5$-null $\left(L h \times 5^{-}\right)$(Zhao et al., 1999), Lhx1 ${ }^{\text {tau-lacz }}\left(\operatorname{Lh} x 1^{\text {tlz }}\right)$ (Kania et al., 2000), and Ebf2-GFP (GENSAT; http://www.gensat.org/) (Gong et al., 2003). Mice were crossed to generate mutant embryos lacking $\operatorname{Lh} \times 5$ function $\left(\operatorname{Lh} \times 5^{-/-}\right.$or $\left.L h x 5^{-1-} ; L h x 1^{t l z}\right)$. Controls were either wild-type or heterozygous littermates. Genotyping was performed by PCR using primers and conditions referenced for each mouse line. The day of detection of the vaginal plug was considered as embryonic day 0.5 (E0.5). Staging of the embryos was confirmed using limb development as a reference (Kaufman, 1992). For whole-embryo cultures, wild-type and $L h \times 5^{-1-}$ mutant embryos in CD1 or C57/B6 background were used. Pregnant, females were killed by cervical dislocation or using $\mathrm{CO}_{2}$ with minimum distress for the animal. Animals were housed and handled in compliance with National Institutes of Health regulations, Mexican governmental guidelines regarding the use of laboratory animals for research purposes NOM-062-ZOO1999, the University of California Chancellor's Animal Research Committee, the European Commission guidelines (86/609/CEE), and the committee for animal care and use of the Cajal Institute.

Tissue preparation. Embryos were fixed in 4\% paraformaldehyde (PFA) overnight at $4^{\circ} \mathrm{C}$ and washed in PBS. Brains were extracted and the telencephalic vesicles were carefully isolated. To prepare frozen sections, tissue was submerged in 30\% sucrose/PBS overnight and embedded in TissueTek OCT compound (Bayer). Coronal sections (10 $\mu \mathrm{m})$ were cut and mounted on Superfrost Plus slides (Thermo Fisher Scientific), dried for $30 \mathrm{~min}$, and stored at $-70^{\circ} \mathrm{C}$. For histological analysis, brains were dehydrated, embedded in paraffin, and sectioned $(20 \mu \mathrm{m})$. The sections were rehydrated and Nissl-stained following standard protocols.

In situ hybridization. Single chromogenic and double fluorescent in situ hybridization (FISH) was performed as described previously (Varela-Echavarría et al., 1996; Ramírez-Amaya et al., 2005). Digoxigenin (DIG) or fluorescein (FITC)-labeled antisense riboprobes were synthesized by in vitro transcription using the following cDNA templates: Cux2 and Er81 (Zimmer et al., 2004), Lhx1 (Fujii et al., 1994), Lhx5 (Sheng et al., 1997), reelin (D’Arcangelo et al., 1997), Wnt3a (Parr et al., 1993), Wnt5a (Muzio and Mallamaci, 2005), and the IMAGE clones (Invitrogen): Ebf2 (no. 6306804), p21 (no. 5326128), p73 (no. 6826464), and Tbr1 (no. 6817237). For double FISH, DIG-labeled Lhx5 or Ebf2 probe was mixed with FITC-labeled reelin probe during the hybridization step and detected sequentially. Detection was performed essentially as described by Ramírez-Amaya et al. (2005), with some modifications. After RNase A treatment, quenching of endogenous peroxidase was performed by using $1 \% \mathrm{H}_{2} \mathrm{O}_{2} / 1 \times$ SSC. The slides were then incubated for 30 min in blocking reagent (TSA with 5\% goat serum; PerkinElmer Life and Analytical Sciences). Overnight incubation with an anti-DIG-HRP antibody (Roche; 1:800 in TSA) was performed at $4^{\circ} \mathrm{C}$. Slides were washed in Tris-buffered saline (supplemented with $0.05 \%$ Tween 20) (TBS-T), and signal was revealed with a cyanine 3 substrate kit (PerkinElmer Life and
Analytical Sciences), 1:100 for $45 \mathrm{~min}$. Sections were then treated with $1 \% \mathrm{H}_{2} \mathrm{O}_{2}$ /TBS to quench residual HRP activity. Incubation with antiFITC-HRP antibody (Jackson ImmunoResearch; 1:400 in TSA) was performed overnight at $4^{\circ} \mathrm{C}$. After washing in TBS-T, the FITC-HRPconjugated antibody was detected using a FITC substrate kit (PerkinElmer Life and Analytical Sciences), 1:100 for $15 \mathrm{~min}$. Nuclear counterstaining was performed with 4',6-diamidino-2-phenylindole (DAPI) (1:500 in TBS) before slide mounting (Vectashield Mounting Medium; Vector Laboratories).

$X$-gal staining and immunohistochemistry. Sections were washed in PBS, blocked in $5 \%$ heat-inactivated goat serum/0.1\% Tween 20/PBS for $1 \mathrm{~h}$, and incubated with primary antibodies overnight at $4^{\circ} \mathrm{C}$ in the same solution. Sections were then washed with PBS and incubated for $1 \mathrm{~h}$ with fluorophore-conjugated secondary antibodies. For detection of bromodeoxyuridine (BrdU), sections were treated additionally with $2 \mathrm{~N} \mathrm{HCl}$ for $20 \mathrm{~min}$ at $37^{\circ} \mathrm{C}$, neutralized with $0.1 \mathrm{M}$ borate buffer, $\mathrm{pH} 8.5$, for 10 min, washed with PBS, and then processed for immunohistochemistry (IHC). To analyze the expression of $\beta$-galactosidase ( $\beta$-gal), brains were fixed for $30 \mathrm{~min}$ and processed for X-gal staining prior sectioning. The following antibodies were used for IHC: mouse monoclonal anti-reelin [164-496; Calbiochem; MAB5364 (clone G10); Millipore Bioscience Research Reagents]; rabbit anti-Lhx1/Lhx5 (Tsuchida et al., 1994); rabbit anti-Lhx1 (Poché et al., 2007); goat anti- $\beta$-gal (4600-1409; Biogenesis), rabbit anti-calbindin D-28K (CB38; Swant), rabbit anti-calretinin (7699/4; Swant), rabbit-anti-Tbr1 (AB9616; Millipore Bioscience Research Reagents), and mouse monoclonal anti-BrdU (347580; BD Biosciences). Secondary antibodies coupled to Alexa 488, 546, 568, and 594, and Alexa 488 and 568-streptavidin were from Invitrogen. Biotin-SPAffiniPure goat anti-rabbit and goat anti-mouse IgG $(\mathrm{H}+\mathrm{L})$ were from Jackson ImmunoResearch.

BrdU labeling. A BrdU solution $(10 \mathrm{mg} / \mathrm{ml})$ was injected intraperitoneally $(100 \mathrm{mg} / \mathrm{kg})$ into pregnant mice at E11.5. After $30 \mathrm{~min}$, pregnant mice were killed by cervical dislocation, and embryos were rapidly extracted and fixed in 4\% PFA/PBS followed by chromogenic in situ hybridization (ISH) and IHC, as described above.

Whole-embryo cultures. The procedure for embryo culture has been described in detail previously (de Carlos et al., 1996). A 10 mm solution of carboxy-fluorescein diacetate succinimidyl ester in DMSO (CFDA SE) (557 molecular weight; V12883; Invitrogen) was injected with the aid of a pressure device under a dissecting microscope. The injected embryo was transferred to a glass bottle containing $4 \mathrm{ml}$ of culture medium, which was placed in a rotor housed in an incubator for $1 \mathrm{~d}$ at $36^{\circ} \mathrm{C}$ with continuous gassing $\left(95 \% \mathrm{O}_{2}, 5 \% \mathrm{CO}_{2}\right)$. The embryos were cultured in heat-inactivated rat serum obtained by centrifugation of blood immediately after extraction from adult donor animals. Serum was filtered through a $0.45 \mu \mathrm{m}$ filter and supplemented with $2 \mathrm{mg} / \mathrm{ml}$ glucose and $200 \mathrm{IU} / \mathrm{ml}$ penicillin-streptomycin mix (Invitrogen) just before use.

Image acquisition. Bright-field and fluorescence images were obtained under Nomarski/bright-field and fluorescence/confocal microscopy, respectively, and processed with Adobe Photoshop software (Adobe Systems) equally for all genotypes analyzed. For double ISH/IHC (supplemental Fig. 1, available at www.jneurosci.org as supplemental material), fluorescence and bright-field hybridization images were sequentially acquired from the same field. The bright-field image was digitally converted into a false-color image and displayed alone or merged with the fluorescence image for comparison. For confocal images, a 3-6 $\mu \mathrm{m}$ confocal slice was scanned sequentially for the different emissions and averaged $(n=8)$ using an inverted Zeiss LSM 510 Meta confocal microscope (Carl Zeiss).

Signal quantification and statistical analysis. ISH signal with the DIGlabeled reelin riboprobe was analyzed semiquantitatively by determining pixel intensity of the reaction product using the NIH ImageJ software. Telencephalic vesicles of E12.5 mutant $(n=6)$ and control $(n=6)$ embryos were subjected to ISH in equal conditions. Bright-field pictures of laterally oriented whole brains were acquired with identical lighting and camera settings, and a $0.16 \mathrm{~mm}^{2}$ square box at the lateral cortex was selected for analysis. For each individual telencephalic hemisphere, the positioning of the square was achieved by drawing a line at its base and making a triangle by extending two lines at $45^{\circ}$ with respect to the base 


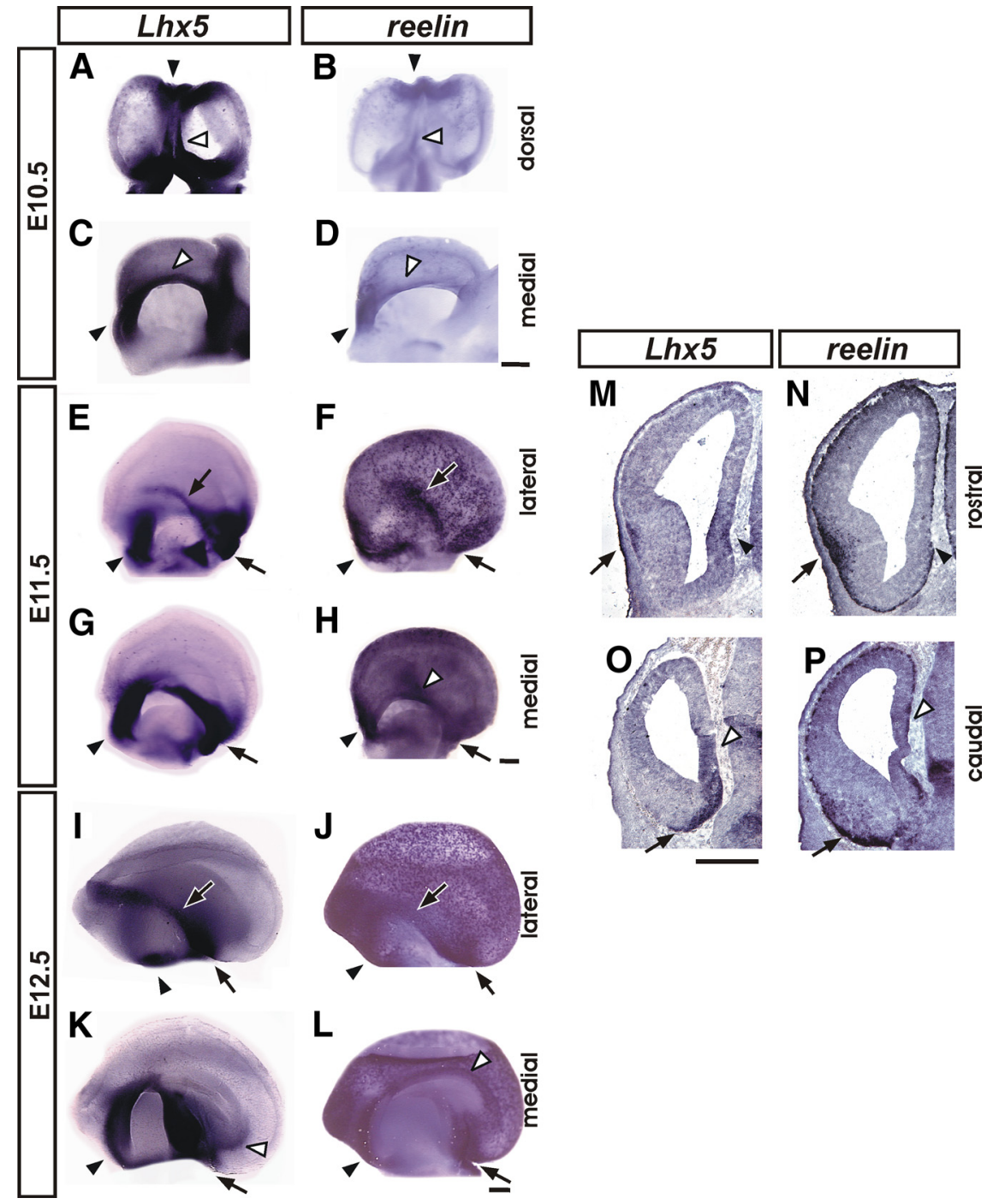

Figure 1. Lhx5 and reelin expression in the developing mouse telencephalon. Expression was analyzed by whole-mount in situ hybridization on telencephalic vesicles from E10.5 (A-D), E11.5 (E-H), and E12.5 (I-L), shown in dorsal, medial, and lateral views as indicated (rostral is to the top in $\boldsymbol{A}$ and $\boldsymbol{B}$ and to the left in $\boldsymbol{C}-\boldsymbol{L}$ ). $\boldsymbol{M}-\boldsymbol{P}, \mathrm{E} 12.5$ coronal telencephalic sections of comparable rostral $(\boldsymbol{M}, \boldsymbol{N})$ and caudal $(\mathbf{O}, \boldsymbol{P})$ levels were analyzed by ISH for $\operatorname{Lh} \times 5(\boldsymbol{M}, \mathbf{0})$ and reelin $(\boldsymbol{N}, \boldsymbol{P})$ (medial to the right). The black arrowheads point to the septal domain; the black arrows indicate the location of the pOC domain, and the white arrowheads mark the location of the cortical hem. Scale bars: $\boldsymbol{A}-\boldsymbol{D}, 400 \mu \mathrm{m} ; \boldsymbol{E}-\boldsymbol{P}, 200 \mu \mathrm{m}$.

line. The square was then centered at the crossing of the lines as shown in Figure 3, $E$ and $F$. Individual images obtained from each selected square were equally processed with Adobe Photoshop to improve signal-tonoise ratio. Images were further analyzed by a blind experimenter using the Multithreshold Isodata plug-in of the ImageJ software that allowed the detection of above-threshold pixels as positive signal (see Fig. $3 E^{\prime}, F^{\prime}$, red label). The relative proportion of pixels above and below threshold was expressed as a percentage of the area covered by signal. Statistical analysis using the SPSS software (SPSS) was performed by applying an unpaired $t$ test to the data, giving a significant difference between groups with a value of $p<0.005$.

\section{Results}

$L h x 5$ is expressed in reelin-expressing territories in the developing mouse telencephalon

To determine the expression patterns of $L h \times 5$ in relation to the proposed sites for C-R cell generation, we performed wholemount ISH on the telencephalon from E10.5 to E12.5, the time window of C-R cell production in the mouse (Hevner et al.,
2003). The expression of reelin, a specific marker for C-R cells, was analyzed in parallel.

As described previously (Zhao et al., 1999), Lhx5 was strongly expressed in the dorsal telencephalic midline at E10.5 throughout the whole thickness of the medial neuroepithelial wall, including the cortical hem and the ventrally located choroid plexus territory. In addition, $L h x 5$ was expressed in the septal area and in scattered cells in the dorsal telencephalon (Fig. $1 A, C$ ). The septal expression consisted of a continuous domain from the septum to the lateral side of the rostroventral telencephalon around the retrobulbar region. At this early stage, reelin ${ }^{+}$cells were concentrated at the rostral pole, although faint expression could already be detected at the caudomedial telencephalic wall (CMTW) (Fig. 1B,D).

At E11.5, the expression of $L h x 5$ persisted in the septal area and at the rostral and caudal ends of the cortical hem (Fig. $1 G)$. A clearly discernible stripe of $L h x 5^{+}$ cells was detected superficially in a lateral region corresponding to the prospective olfactory cortex (pOC). This domain of expression seemingly followed the lateral olfactory tract (LOT), curving caudally and ventrally reaching a site in the ventral region of the CMTW adjacent to its boundary with the diencephalon (vCMTW) (Fig. $1 E, G$, arrows). Interestingly, the region occupied by the lateral component of this domain appeared to coincide with the location of the reelin ${ }^{+}$domain derived in part from the $D b x 1^{+}$-lineage at the VP/ PSB (Fig. 1F) (Bielle et al., 2005). Moreover, reelin was found to be expressed in the septal area and, to a lesser extent, in the cortical hem, resembling the expression of Lhx5. In contrast to Lhx5, many reelin ${ }^{+}$cells were also detected in neocortical regions, confirming that migration of $\mathrm{C}-\mathrm{R}$ cells is already taking place at this stage (Takiguchi-Hayashi et al., 2004; Bielle et al., 2005; Yoshida et al., 2006; García-Moreno et al., 2007).

ISH analysis on E12.5 brains in whole mount and in sections showed that $L h x 5$ and reelin were expressed in the domain that spans the pOC and extends into the vCMTW as well as in the septal region at the borders of the telencephalon. In the cortical hem, whereas reelin was expressed at all rostrocaudal levels, $L h \times 5$ was only expressed at its caudalmost end (Fig. $1 I-P$ ). At this stage, numerous reelin- and few Lhx5-positive cells were found scattered in the dorsal telencephalon (Fig. $1 I-P$ ). Comparing the medial telencephalic expression of Lhx5 between E11.5 and E12.5, it can be noted that the expression in the cortical hem becomes restricted to its caudoventral part by E12.5 and that the domain in the vCMTW appears to recede ventrally (Fig. $1 G, K$ ). This contrasts with the expression of Lhx5 spanning the whole extent of the cortical hem neuroepithelium at earlier stages (Fig. $1 C, G)$. Expression of $L h x 5$ by this stage appeared generally in the 
outermost layer of the developing telencephalon, suggesting that it is mainly confined to postmitotic cells except in restricted rostral septal and caudomedial regions (Fig. $1 M, O)$. This was addressed directly by labeling mitotically active cells with a $30 \mathrm{~min}$ BrdU pulse followed by Lhx5 ISH and BrdU immunodetection in E11.5 embryos. This analysis revealed that the $L h x 5^{+}$cells occupying the mantle zone at olfactory and caudal septal regions were not labeled by BrdU and, hence, were not proliferating (supplemental Fig. $1 C, D$, available at www. jneurosci.org as supplemental material).

Given the similarities between the expression patterns of Lhx5 and reelin, we asked whether $L h x 5^{+}$cells in the developing telencephalon also expressed reelin. Using double FISH, we were able to detect extensive cellular colocalization of $L h x 5$ and reelin transcripts in the marginal zone of the septal and pOC domains at E12.5 (Fig. 2A-C) (data not shown). By this stage, the expression of $L h \times 5$ in the cortical hem is dramatically reduced compared with the high expression level observed at earlier stages, before the onset of reelin expression.

To examine cellular colocalization with reelin proteins, we performed double immunostaining on sections of E12.5 embryos with an antibody that recognizes both Lhx5 and Lhx1, and an antibody against reelin. As shown in Figure 2, $D$ and $E$, Lhx5/1 ${ }^{+}$nuclei were found in reelin ${ }^{+}$cells in the marginal zone of both the septal and pOC regions (see below for description of Lhxl expression).

\section{Deletion of $L h x 5$ causes reduction and abnormal distribution of Cajal-Retzius cells}

Based on the observation of $L h \times 5$ expression at the dorsal telencephalic midline including the cortical hem and later in the ree$\operatorname{lin}^{+}$cells in the marginal zone in the septum, olfactory cortex, and ventromedial telencephalon, we hypothesized that proper development of subsets of reelin ${ }^{+}$cells is dependent on $\operatorname{Lh} \times 5$ function. To determine such role, we analyzed null-mutant embryos lacking $L h \times 5$ function (Zhao et al., 1999). The telencephalon of mutant embryos was often slightly smaller than that of control littermates. Using whole-mount ISH, we found a marked reduction in expression of reelin in the cortical hem as well as in the septal and pOC regions of $L h \times 5$ mutants (Fig. 3). As early as E11.5, numerous C-R (reelin ${ }^{+}$) cells were normally found throughout the cortical neuroepithelium (Fig. $3 A$ ). In contrast, only few such cells could be detected in the Lhx5 mutant, and these were mainly located at the caudal telencephalic pole (Fig. $3 B$ ). This difference was more pronounced at E12.5 (Fig. 3E-H). Quantification of reelin ISH signal revealed a significant reduction in mutants compared with control littermates (control, 41.2\%; mutant, $15.6 \%$; $p<0.005$ ) (Fig. $3 E, F$ ). Notably, at the caudal telencephalon, ectopic reelin ${ }^{+}$cell clusters were consistently detected in the mutant brains from E11.5 onward $(n=24$ of 24 ) (Fig. $3 B, D, F, H$ ). At E12.5, two reelin ${ }^{+}$ectopic clusters were generally found in the mutant telencephalon: a large one in the caudal pole extending from the medial to the lateral side of the telencephalon, and a small lateral cluster sometimes seen contin- uous to the large cluster. Despite some variability in their dorsoventral location, both clusters seemed to be associated with the reelin $^{+}$domain in the pOC (Fig. $3 F, H$ ). The reduction of the different reelin ${ }^{+}$domains and the presence of reelin ${ }^{+}$cell ectopias at the marginal layer of the caudal telencephalon in $L h \times 5$ mutants were further confirmed by examination of coronal sections of the brain from embryos at E12.5 (Fig. 3I-P).

An additional marker for C-R neurons is p73, a nuclear protein of the $\mathrm{p} 53$ family of tumor suppressors. $p 73$ has been shown to be expressed during early telencephalic development in ree$\mathrm{lin}^{+}$cells, particularly in the septum and cortical hem (Meyer et al., 2004; Yoshida et al., 2006; Inoue et al., 2008; Siegenthaler and Miller, 2008). By whole-mount ISH, we detected $p 73^{+}$cells in control embryos from E10 to E11.5. The $p 73^{+}$cells were present along the dorsal midline from septal to cortical hem regions and throughout the telencephalic vesicle, albeit not as numerous as reelin $^{+}$cells in the same regions (Fig. $4 A, C, E$ ). At E.11.5, p73 expression strongly labeled the vCMTW region, whereas few scattered cells were found along the pOC (Fig. 4C,E). By E12.5, increased $p 73$ expression was observed in the developing neocortex, cortical hem, septum, and in a continuous domain spanning pOC and vCMTW regions (Fig. 4G,I). In contrast, the vCMTW region of $L h x 5$ mutants appeared abnormal from E10.5 to E12.5 by $p 73$ expression; clear malformations were detected as the typical curved shape at the caudal end of the hem territory was missing (Fig. 4B, F,J). Similar to reelin, in E12.5 Lhx5 mutants, decrease in number of $p 73^{+}$cells was observed in the dorsal telencephalon, and in the septal, pOC, and vCMTW regions defined by $L h x 5$ expression (Fig. $4 H, J$ ). Notably, only the rostralmost region of the pOC in the mutant contained $p 73^{+}$cells (Fig. $4 \mathrm{H}$ ). Like reelin, $p 73$ expression labeled a large mediolateral ectopic cell cluster at the caudal telencephalic pole (compare Figs. $3 F, H, 4 H, J)$ and a small lateral domain (Fig. $4 H$ ). Since reelin 


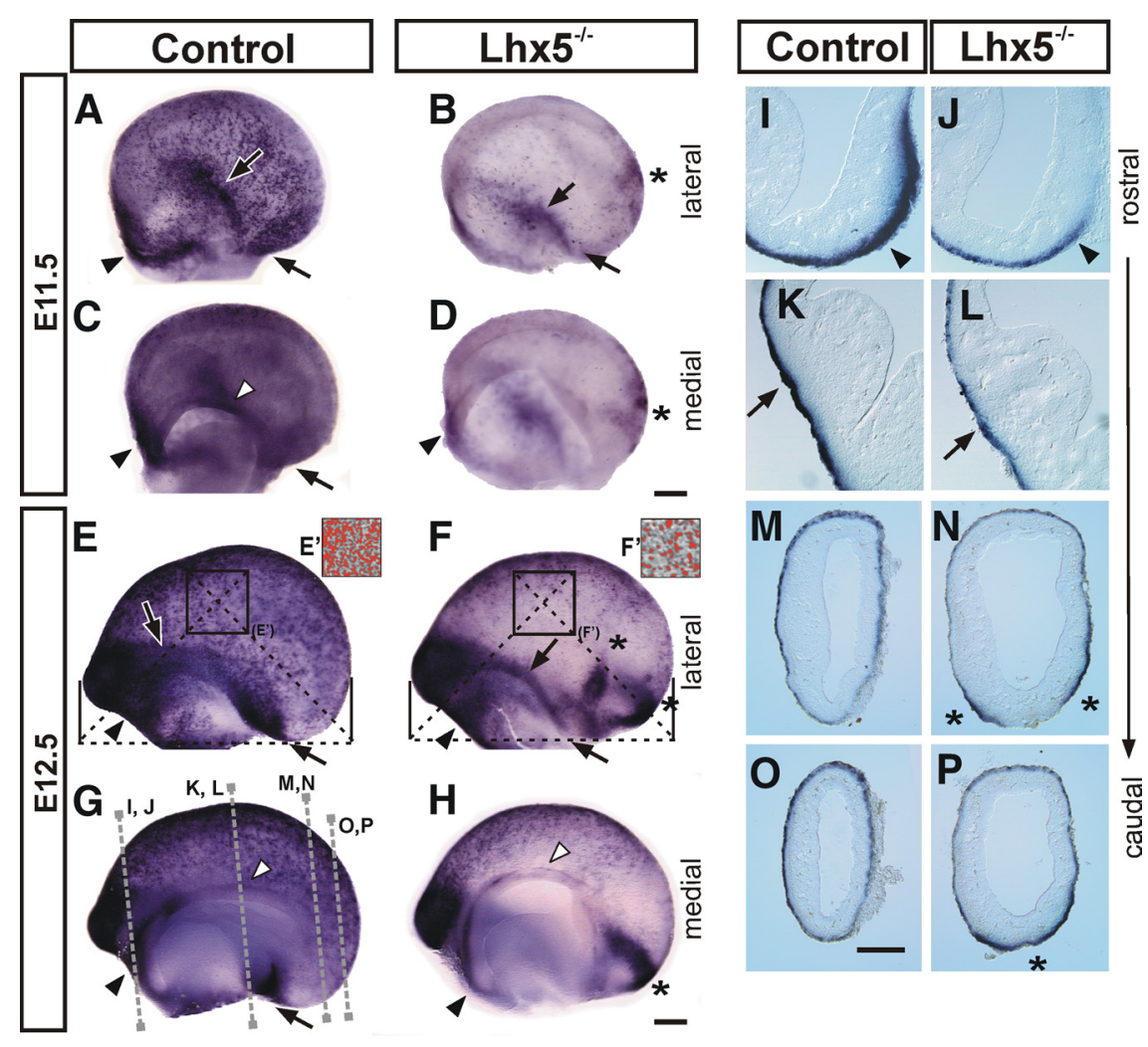

Figure 3. Abnormal development of Cajal-Retzius cells in $L$ hx5-null mutant embryos. Whole-mount reelin in situ hybridization on E11.5 (A-D) and E12.5 $(\boldsymbol{E}-\boldsymbol{H})$ telencephalic vesicles from control and mutant $\left(L h \times 5^{-/-}\right)$littermates. As indicated, lateral and medial views of the telencephalon are shown (rostral is to the left). $\boldsymbol{E}^{\prime}, \boldsymbol{F}^{\prime}$, Overthreshold reelin ${ }^{+}$signal (red overlay) in control and mutant embryos, respectively, obtained from equivalent regions in the lateral cortex $(\boldsymbol{E}, \boldsymbol{F}$, squared boxes) (for details, see Materials and Methods). I-P, Coronal sections showing expression of reelin in control and $L h \times 5^{-1-}$ telencephalic hemispheres at the approximate rostrocaudal levels indicated by dotted lines in $\mathbf{G}$ (medial is to the right). For all panels, Black arrowheads, Septal domain; black arrows, pOC domain; white arrowheads, cortical hem; asterisks, ectopic reelin ${ }^{+}$cell clusters. Scale bar, $200 \mu \mathrm{m}$.

and $p 73$ expression was missing in the caudal cortical hem and in the vCMTW region adjacent to the diencephalon, and a nearby stream of ectopic cells was labeled instead, we deemed likely that the cells of these domains were abnormally located in the mutants.

Variable cellular ectopias were also found later, at E18.5, in the cortex of the Lhx5 mutants. On Nissl-stained sections, we noticed that these ectopias were composed of cell clusters surrounded by cell-free areas, and mostly localized in occipital and perirhinal cortices ( $n=2$ of 2 ) (supplemental Fig. $2 A-C$, available at www.jneurosci.org as supplemental material). Despite the early alterations in C-R cell numbers, preplate splitting and cortical lamination did not seem to be affected in Lhx5 mutants, as assessed by Nissl staining and by the expression of the laminar markers Tbr1, Er81, and Cux2 (supplemental Fig. 2D-G, available at www.jneurosci.org as supplemental material).

In summary, lack of $\operatorname{Lh} \times 5$ function results in a strong reduction in C-R cells in the dorsal telencephalon and a marked decrease in reelin and $p 73$ expression in the cortical hem, septum, pOC, and vCMTW territories at E12.5. Moreover, ectopic cell clusters expressing reelin and $p 73$ were found in the caudal region of the mutant telencephalon from early developmental stages. These results indicate that $L h x 5$ is required for the development and normal distribution of C-R cells.
Lack of $L h x 5$ results in cortical hem shortening and reduction of $p 21^{+}$cells Since the number and distribution of C-R cells was found to be severely affected in Lhx5 mutants, and these mutants display abnormalities in midline structures such as the hippocampus (Zhao et al., 1999), we further analyzed entire telencephalic vesicles for the expression of $W n+5 a$ and Wnt $3 a$, two markers normally expressed in the cortical hem (Yoshida et al., 2006) (Fig. 5). At E11.5, the expression of Wnt5a was absent from most of the hem territory in $L h \times 5$ mutants, in keeping with our previous findings (Fig. $5 A, B$ ) (Zhao et al., 1999). Likewise, Wnt3a expression was dramatically reduced from the cortical hem, although residual expression could be detected rostrally (Fig. 5C,D). Moreover, the cortical selector gene $L h x 2$ (Mangale et al., 2008) was ectopically expressed in the medial telencephalic regions (Zhao et al., 1999), suggesting that most of the cortical hem territory adopts a neocortical fate in the mutants.

We also analyzed the expression of $p 21$, a cyclin-dependent kinase inhibitor expressed in reelin ${ }^{+}$and $p 73^{+}$cells in the septum, cortical hem, and in C-R cells at early stages of their development in the adjacent cortical neuroepithelium (Siegenthaler and Miller, 2008). Consistent with the cortical hem shortening and the decreased number of reelin ${ }^{+}$and $p 73^{+}$cells along the telencephalic midline, fewer $p 21^{+}$cells were found in the septum, cortical hem, and medial telencephalon at E11.5 and E12.5, with the caudal domain of the hem being the most affected (Fig. $5 E-H$ ). Although no ectopic clusters were labeled by $p 21$, aberrant expression was detected in the caudomedial region that appeared to give rise to the large ectopic cell clusters (Fig. $5 F, H$, arrows) (see below).

\section{$L h x 1$ and $E b f 2$ expression identifies subsets of reelin ${ }^{+}$cells affected in $L h x 5$ mutants}

To better dissect the reelin ${ }^{+}$cell phenotype in Lhx5 mutants, we analyzed the expression of Lhxl, a LIM-homeodomain (LIMHD) factor closely related to $L h \times 5$ that is also expressed in C-R cells (Abellan et al., 2010). At E10, scattered $L h x 1^{+}$cells appeared in the rostralmost region of the wild-type telencephalon (data not shown). By E11.5, strong Lhxl expression was found in the septal and vCMTW regions, but it was excluded from the cortical hem (Fig. 6A,C). BrdU labeling at this stage confirmed that $L h x 1$ is expressed in postmitotic cells in the septal and pOC regions (supplemental Fig. $1 A, B$, available at www.jneurosci.org as supplemental material). At E12.5, we detected strong $L h x 1$ expression in the pOC region and in scattered cells in the entire developing cortex (Fig. 6E, G; supplemental Fig. 1E-G, available at www. jneurosci.org as supplemental material). By double labeling of Lhx1 and reelin on sections from wild-type embryos or embryos carrying the $L h x 1^{t l z}$ reporter allele (Kania et al., 2000), we detected Lhx1/reelin-double positive cells in pOC, vCMTW, septal, and neocortical regions (supplemental Fig. $3 A-H$, available at www.jneurosci.org as supplemental material). We also found 


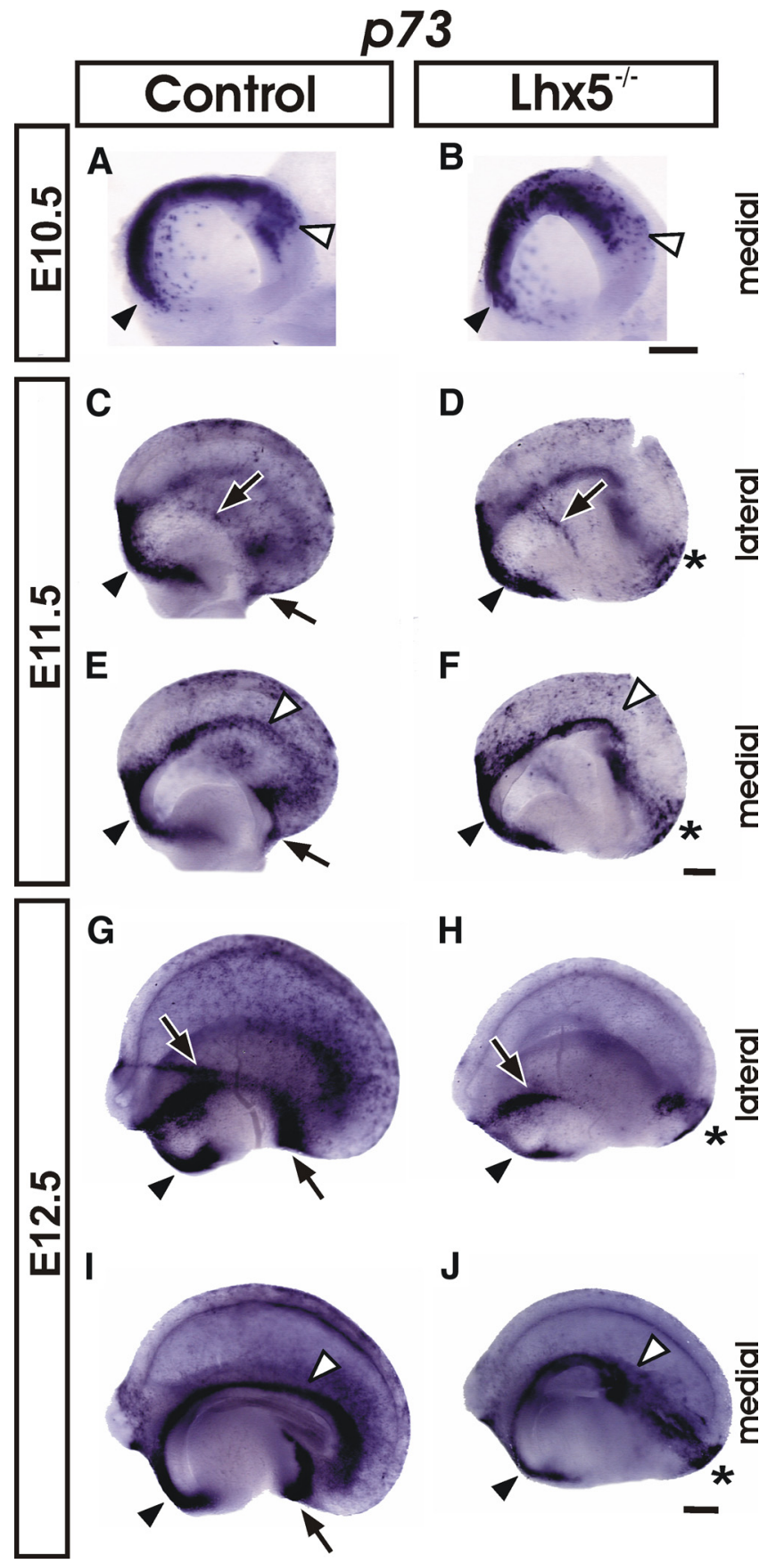

Figure 4. p73 expression is altered in $L h \times 5$ mutants. Whole-mount in situ hybridization on telencephalic vesicles from control and mutant embryos at E10.5 $(\boldsymbol{A}, \boldsymbol{B}), \mathrm{E} 11.5(\boldsymbol{C}-\boldsymbol{F})$, and $\mathrm{E} 12.5$ $(\boldsymbol{G}-\boldsymbol{J})$ (rostral is to the left). The black arrowheads point to the septal domain; the black arrows indicate the location of the $\mathrm{pOC}$ domain; the white arrowheads mark the location of the cortical hem, and the asterisks indicate ectopic cell clusters. Scale bar, $200 \mu \mathrm{m}$.

that cells labeled with the $L h x 1$ reporter in all those regions expressed calretinin, a calcium-binding protein found in a large proportion of C-R cells but also present in other cell types (supplemental Fig. 3I-L, available at www.jneurosci.org as supplemental material). Thus, a subset of $\mathrm{C}-\mathrm{R}$ cells can be readily identified in the developing neocortex by double reelin/Lhx1 expression.

ISH of E11.5 Lhx5 mutants revealed a near-total absence of $L h x 1$ expression in the pOC and a thinner $L h \times 1^{+}$domain in the vCMTW region (Fig. $6 B, D$ ). Interestingly, this last domain ex-

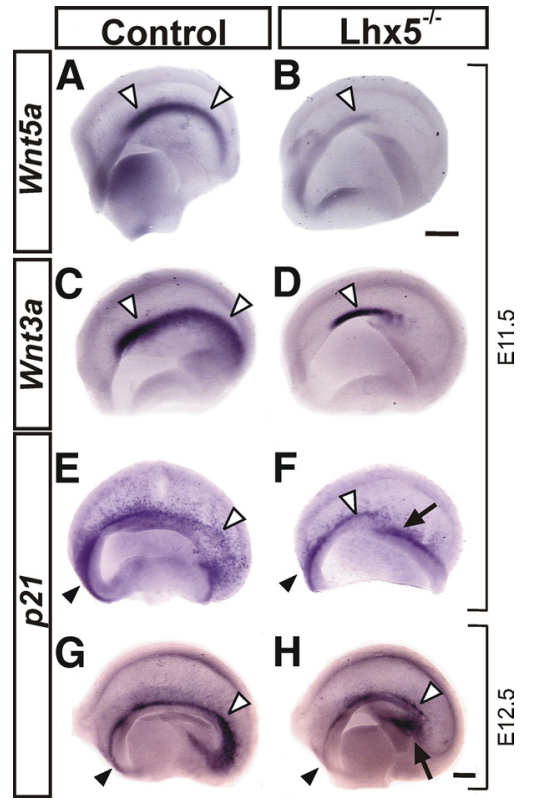

Figure 5. Cortical hem alterations in $L h x 5$ mutants. Medial views of telencephalic vesicles from control and mutant embryos showing the expression of the hem-specific markers Wnt5a $(\boldsymbol{A}, \boldsymbol{B})$ and $W n t 3 a(C, \boldsymbol{D})$ at E11.5. $\boldsymbol{E}-\boldsymbol{H}$, Hem-derived C-R cells labeled by $\mathbf{p} 21$ expression at E11.5 and E12.5. Note the shortening of the cortical hem in Lhx 5 mutants by Wnt3a expression, the dramatic reduction of Wnt5a expression levels, and the decreased numbers of $p 21^{+}$cells in the medial telencephalon of $L h \times 5$ mutants. In all frames, rostral is to the left. The white arrowheads point to the cortical hem, the black arrowheads to the septal region, and the arrows indicate the approximate site of origin of the ectopic cell clusters. Scale bar, $200 \mu \mathrm{m}$.

tended farther dorsally in the mutant than in controls, which appears complementary to the shortening defect of the cortical hem (Figs. $5 A-D, 6 C, D$ ). By E12.5, we observed a dramatic decrease in $L h x 1$ expression in the regions harboring reelin ${ }^{+}$cells in the septal, pOC, and vCMTW territories and in the neocortical primordium (Fig. $6 E-H$ ). Moreover, ectopic cell clusters located at the caudal $L h \times 5^{-1-}$ telencephalon at E11.5 and E12.5 expressed $L h x 1$ (Fig. 6, asterisks). Immunostaining at E12.5 revealed that those clusters coincide with those detected by reelin expression (Figs. $3 E-H, 6 W, X$ ).

Similar results were obtained by analyzing the expression of the $L h x 1^{t l z}$ reporter in relation to the endogenous $L h x 1$ gene expression. We confirmed the dramatic reduction of $L h \times 1^{+}$cells in the $L h x 5$ mutant telencephalon and its presence in caudal ectopias (Fig. $6 I-V$ ). Our results thus reveal $L h x 1$ expression in ree$\mathrm{lin}^{+}$cells in pOC, vCMTW, and septal regions and in a subset of reelin $^{+}$cells in the neocortex whose development is primarily dependent on $L h x 5$ function. Moreover, $\operatorname{Lh} \times 5$ seems to be required for the proper migration of reelin/Lhxl-expressing cells at the caudal telencephalon.

To further evaluate the effect of the lack of $L h \times 5$ in the development of reelin ${ }^{+}$subpopulations, we analyzed the expression of Ebf2, proposed to label VP-derived C-R cells (Yamazaki et al., 2004; Hanashima et al., 2007). We first evaluated the presence of Ebf2 in C-R cells and in pOC regions by double FISH in control embryos and by reelin immunostaining of embryos carrying the green fluorescent protein (GFP) reporter gene expressed from the Ebf2 promoter. Expression of Ebf2 was detected in reelin ${ }^{+}$ cells in the pOC and in most reelin ${ }^{+}$cells in the surface of the developing neocortex at E12.5 (Fig. 7A-E). We also compared expression of Ebf2 in the telencephalon of $L h \times 5$ mutant and control littermates by whole-mount ISH (Fig. $7 F-M$ ). In E11.5 con- 


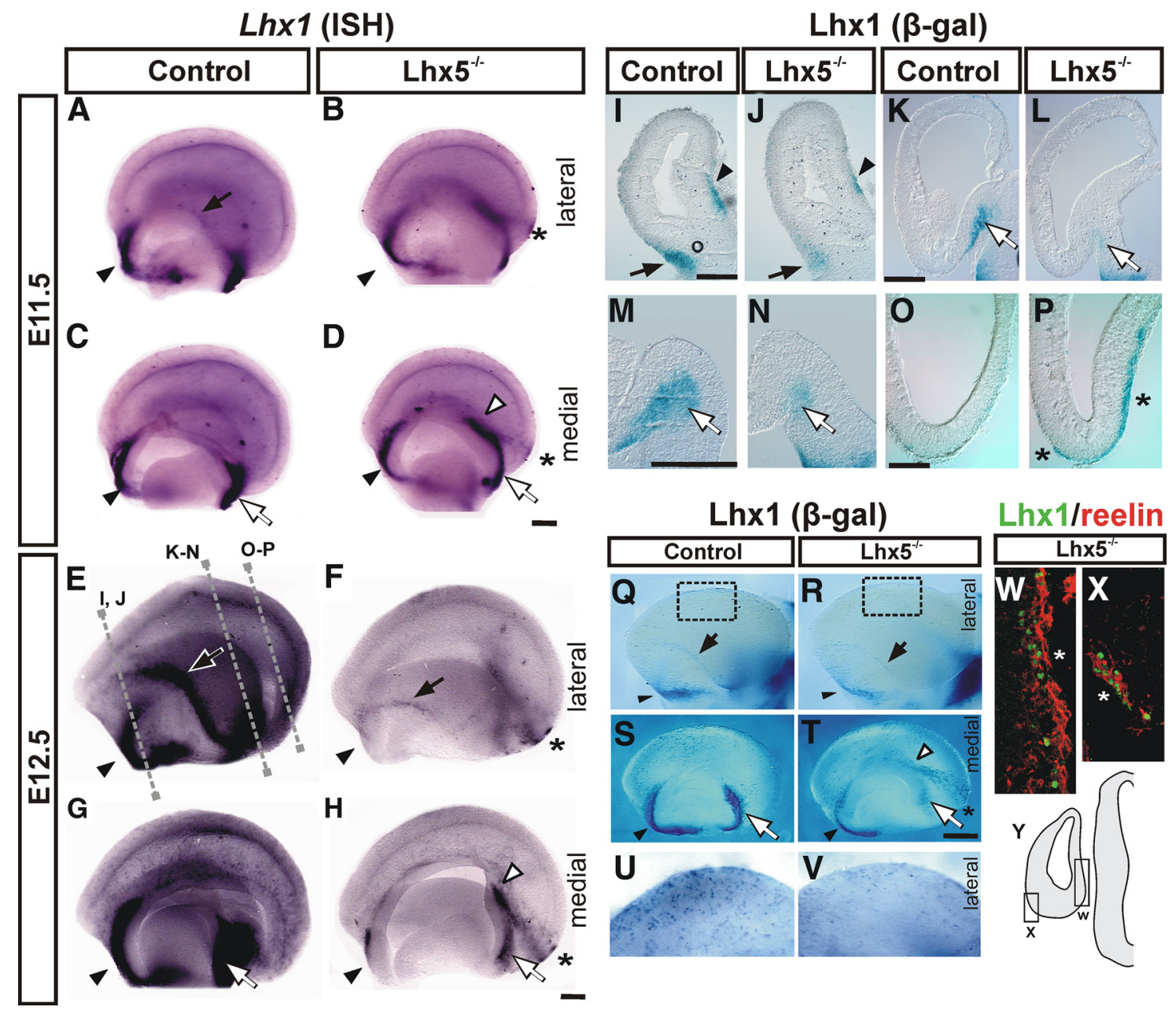

Figure 6. Lhx1 labels specific C-R cell subpopulations affected by $L h \times 5$ mutation. $\boldsymbol{A}-\boldsymbol{H}$, Whole-mount $L h x 1$ in situ hybridization of control and $L h \times 5$ mutants at E11.5 (A-D) and E12.5 (E-H). Medial and lateral views of the telencephalon are shown (rostral is to the left). $I-V$, Detection of $L a c Z$ activity from the $L h x t^{\text {tlz }}$ allele by X-gal staining on coronal sections $(I-P$; approximate locations of the sections are indicated by dotted lines in $\boldsymbol{E}$ ) and whole telencephalic preparations $(\boldsymbol{Q}-\boldsymbol{V})$ from $\mathbf{E} 12.5$ control and $L$ hx 5 mutant embryos. $\boldsymbol{U}$ and $\boldsymbol{V}$ show higher magnification views of the dorsal cortex from boxed areas in $\mathbf{Q}$ and $\boldsymbol{R}$, respectively. $\boldsymbol{W}, \boldsymbol{X}$, Double immunostaining of reelin (red) and Lhx1 (green) in a caudal telencephalic coronal section. The diagram in $Y$ indicates location of ectopic clusters shown in $\boldsymbol{W}$ (lateral) and $\boldsymbol{X}$ (medial). For all panels: Black arrowheads, Septal region; white arrowheads, ectopic $L h \times 1^{+}$cells; black arrows, p0C domain; white arrows, medial expression domain at the VCMTW; asterisks, ectopic cell clusters. Scale bar, $200 \mu \mathrm{m}$.

trol embryos, strong Ebf2 signal was detected throughout the telencephalic vesicle. At E12.5, the signal was particularly strong in the pOC and vCMTW regions (Fig. $7 F, H, J$ ). Analysis of $L h \times 5$ mutants revealed decreased expression in the lateral and caudal neocortical territories at E11.5, although in pOC regions it seemed unchanged at E12.5. Notably, marked Ebf2 expression was detected in ectopic cell clusters at this stage (Fig. 7I, K). Large mediolateral and small lateral clusters were detected by Ebf2 expression as with the reelin probe.

\section{Ectopic reelin ${ }^{+}$cell clusters in the caudal $L h x 5^{-1-}$}

telencephalon originate from the caudomedial telencephalic wall

Seeking evidence to determine the origin of ectopically migrating cells, we performed lineage tracing experiments in cultured whole mouse embryos. The fluorescent permeable tracer CFDA was first injected in the germinative ventricular zone in the caudal part of the cortical hem (Fig. 8A, B; supplemental Fig. 4A-1, available at www.jneurosci.org as supplemental material). We assessed the migratory behavior of cells derived from this region at E11.5 after $24 \mathrm{~h}$ of in toto culture. In keeping with our previous results (García-Moreno et al., 2007), we found that injections in the cortical hem of control embryos label groups of cells that migrate tangentially toward the neocortex in a rostrolateral direction. In contrast, equivalent injections in $L h \times 5$ mutant embryos labeled cells that failed to migrate tangentially and stayed close to the injection site (Fig. 8A,B; supplemental Fig. 4B-1, available at www.jneurosci.org as supplemental material). Notably, labeled cells were not found at ectopic positions in the mutant telencephalon. These data suggest that, at least $24 \mathrm{~h}$ after injection, the extent of cell migration from the caudal cortical hem is hampered in Lhx5 mutant embryos, a finding that is consistent with the hem abnormalities detected by gene expression analysis.

We then applied the fluorescent tracer focally in E11.5 mutant embryos at the apparent site of origin of ectopically migrating cells that form the large cluster to determine their origin. The injection site in the ventricular zone was directed to the dorsal end of the Lhx1, p73, and reelin expression domain in the vCMTW region (Fig. 8C,D; supplemental Fig. $4 B-2$, available at www.jneurosci.org as supplemental material). When making this injection, we took into account that, as described above, this domain extended farther dorsally in the mutants than in wildtype embryos. After $1 \mathrm{~d}$ of in toto culture, labeled cells in Lhx5 

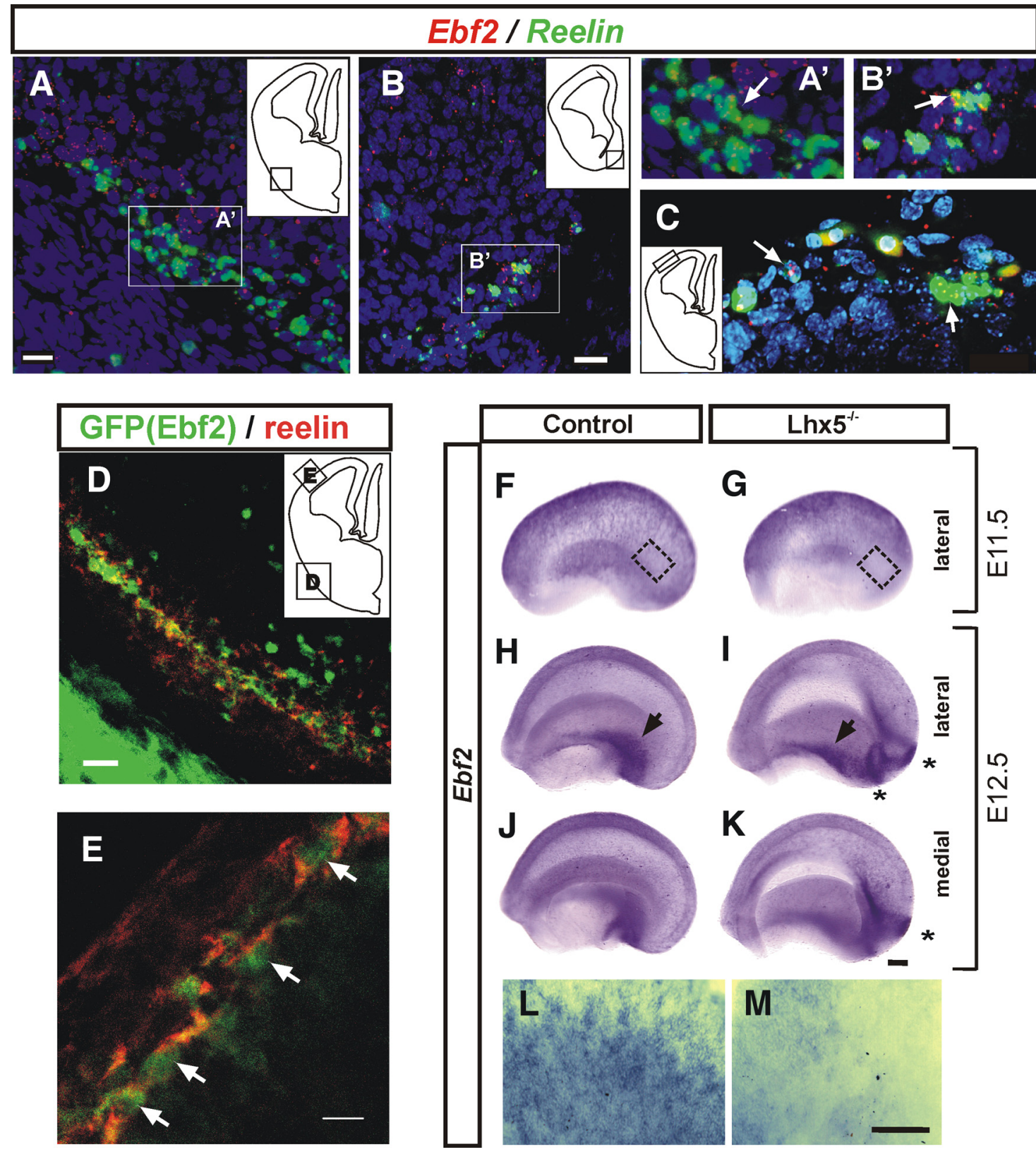

Figure 7. Expression of Ebf2 in C-R cells is affected in $L$ hx5 mutants. $\boldsymbol{A}-\boldsymbol{C}$, Double FISH of Ebf2 (red) and reelin (green) showing cellular colocalization at E12.5. DAPI (blue). $\boldsymbol{A}$, pOC. $\boldsymbol{B}, \mathrm{VCMTW}$. $\boldsymbol{A}^{\prime}$ and $\boldsymbol{B}^{\prime}$ are magnified views of the boxed areas in $A$ and $B$, respectively. $C$, Colocalization in mantle regions of the lateral pallium. Examples of cellular colocalization are indicated by arrows. $D, E$, Confocal images of the pOC domain and marginal zone of the lateral pallium from E12.5 embryos, respectively, showing that Ebf2-GFP ${ }^{+}$cells (green) coexpress reelin (red). The insets in $A-D$ indicate the location of the fields shown in each image. $\boldsymbol{F}-\boldsymbol{M}, \mathrm{E} 11.5$ and $\mathrm{E} 12.5$ telencephalic vesicles from control $(\boldsymbol{F}, \boldsymbol{H}, \boldsymbol{J})$ and $L h \times 5$ mutant $(\boldsymbol{G}, \boldsymbol{I}, \boldsymbol{K})$ littermates analyzed by whole-mount in situ hybridization (rostral to the left; medial and lateral views as indicated). $\boldsymbol{L}, \boldsymbol{M}$, High magnification of lateral cortex at E11.5 as indicated by insets in $\boldsymbol{F}$ and $\mathbf{G}$, respectively. Black arrows, pOC domain; asterisks, ectopic reelin ${ }^{+}$cell clusters. Scale bar, $200 \mu \mathrm{m}$.

mutants were found to migrate caudally in a pattern similar to that suggested by the ectopic expression of reelin, $p 73, L h x 1$, and Ebf2 $(n=3)$ (compare Fig. $8 C, D$, with Figs. $3 H, 4 J, 6 H, 7 K)$. Moreover, most aberrantly migrating cells expressed reelin and were localized at the caudomedial cortex, at a location where reelin $^{+}$cell ectopias were found by ISH (Fig. $8 E-H$ ). These experiments indicate that, in $L h \times 5$ mutants, reelin ${ }^{+}$cells originating at E11.5 from the vCMTW region migrate aberrantly and form ectopic clusters in the caudal telencephalon.

\section{Ventral migratory route of reelin ${ }^{+}$cells originated at the caudomedial telencephalon}

The demonstration that ectopic clusters of reelin ${ }^{+}$cells derive from the vCMTW region in Lhx5 mutants suggested that this region could normally contribute to migratory reelin ${ }^{+}$cells in the nearby territory. Moreover, a previous study revealed the migration of reelin ${ }^{+}$cells from a broad region in the CMTW to the lateral telencephalon via a ventral route (Takiguchi-Hayashi et al., 2004). To map the site of origin of these migratory cells, we performed fluorescent tracer injections in E11.5 wild-type embryos and then cultured the embryos for $24 \mathrm{~h}(n=6)$. Injections in the ventricular zone were directed to the vCMTW region (supplemental Fig. 4A-2, available at www.jneurosci.org as supplemental material) and showed labeled cells that migrated radially to the external layer of the telencephalon and then tangentially in a ventral and lateral route around its caudal pole to converge rostrally in the pOC (Fig. 9A-I). The region populated by these caudomedial-derived cells likely corresponds to the primordium 

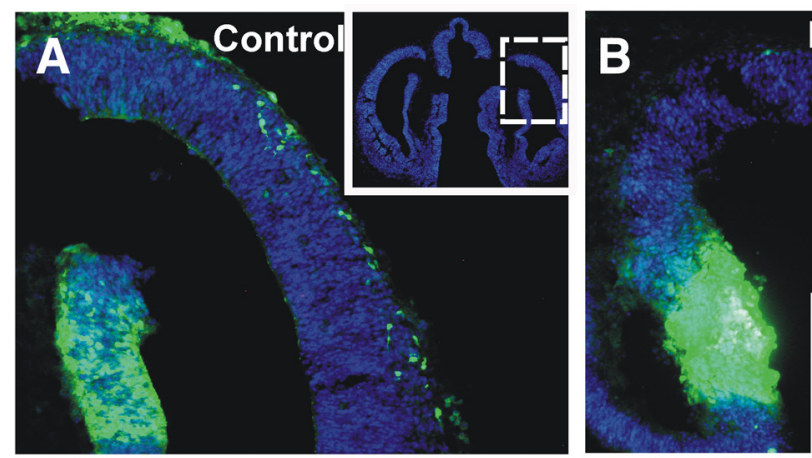

\section{Lhx5}
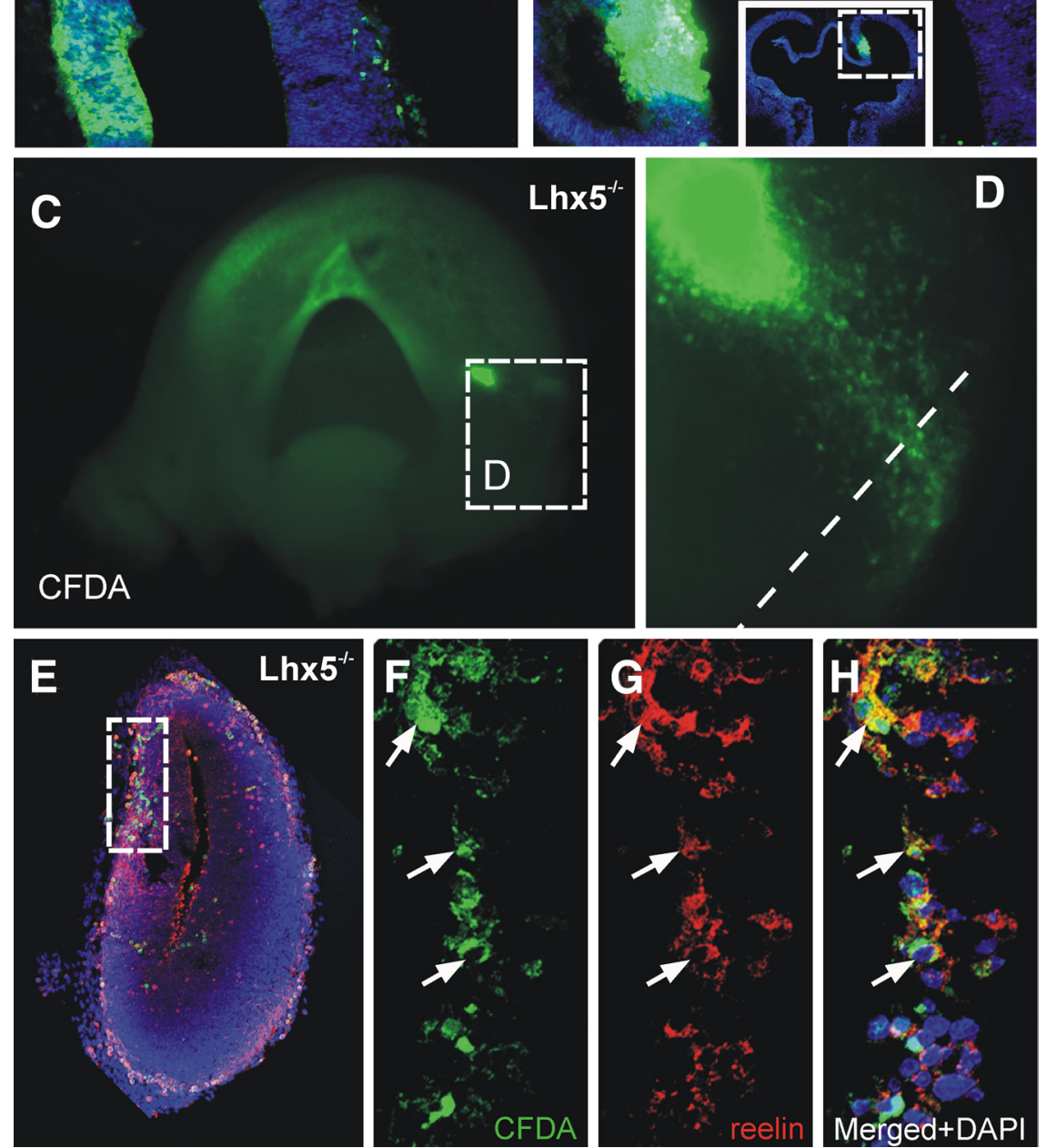

Figure 8. Reelin-expressing cells migrate aberrantly in $L h \times 5$ mutants. $\boldsymbol{A}, \boldsymbol{B}$, Coronal sections of E11.5 control and mutant embryos injected with CFDA (green) in the cortical hem and cultured for $24 \mathrm{~h}$. Migrating cells in the mutant migrate scarcely toward the dorsal telencephalon (insets show location of images in $\boldsymbol{A}$ and $\boldsymbol{B}$ ). $\mathbf{C}-\boldsymbol{H}, \mathrm{Lh} \times 5$ mutant embryo injected at the origin of the cellular ectopia and cultured in toto for $24 \mathrm{~h}$. C, Medial view of a telencephalic vesicle showing the injection site at the vCMTW region (rostral is to the left). $\boldsymbol{D}$, Magnified view of the boxed area in ( showing cells migrating toward the caudal pole of the telencephalon. $\boldsymbol{E}-\boldsymbol{H}$, Immunostaining of Reelin on coronal sections of the same injected embryo (dotted lines in $\boldsymbol{D}$ indicate the approximate plane of section). $\boldsymbol{F}-\boldsymbol{H}$, Confocal optical section of the boxed area in $\boldsymbol{E}$, showing (FDA-labeled cells (green) expressing reelin (red); DAPI (blue). The arrows point to examples of cellular colocalization.

of entorhinal and piriform cortices and matched with mantle regions labeled by reelin, $p 73, L h x 5, L h x 1$, and Ebf2 expression (Figs. 1, 4, 6, 7). To further characterize the migratory cells along this path, we performed immunohistochemical analysis of the CFDA-injected brains using several markers (Fig. 9J-O). Migratory cells appeared to belong to a pallial lineage, since most of them expressed the marker Tbr1 (Fig. 9L) (Hevner et al., 2001, 2003). Moreover, $\sim 50 \%$ of the labeled cells expressed reelin and calretenin (Fig. 9 K, M-O) and did not express calbindin (Fig. 9J), an expression profile suggestive of C-R cells (Hevner et al., 2003; Stoykova et al., 2003; García-Moreno et al., 2007). These data show that the vCMTW region adjacent to the diencephalontelencephalon border gives rise to a number of migratory cells,

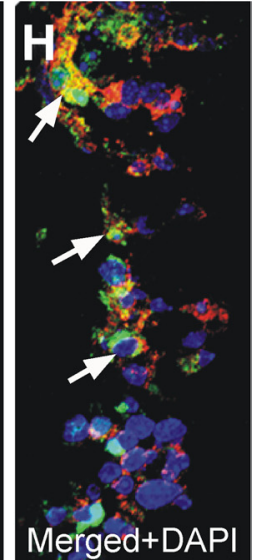

including reelin-positive cells, that are born at E11.5 and travel long distances along the pOC, where they remain at least up to E12.5.

\section{Discussion}

In this study, we investigated the role of LIM-HD transcription factors Lhx5 and Lhx1 in the development of Cajal-Retzius cells in mice. We were able to identify three main regions rich in reelin expression at or adjacent to proposed sites of origin of C-R cells: rostrally, in the septal/ retrobulbar area; medially, in the cortical hem; and laterally, near the VP/PSB region in a continuous domain also extending medially into the ventral CMTW region adjacent to the diencephalon. $L h x 1$ and $L h \times 5$ were expressed in reelin ${ }^{+}$cells in septal, pOC, and vCMTW regions as well as in the neocortical anlage. The cortical hem, main source of C-R cells, expressed high levels of Lhx5 but lacked Lhxl expression at early developmental stages (E10.5-E11.5).

The deletion of $L h \times 5$ resulted in a drastic reduction of C-R cells throughout the neocortex from early stages as assessed by the expression of reelin, p73, Lhx1, and Ebf2. Moreover, whereas the septal, pOC, and vCMTW regions showed decreased expression of these markers, it was the telencephalic midline that appeared more severely affected. As early as E10.5, $p 73^{+}$ cells were found in aberrant positions at the caudal region of the telencephalon. This correlates with the impairment in dorsal midline specification in $L h \times 5 \mathrm{mu}-$ tants revealed by the medial expansion of neocortical regions $\left(\operatorname{Lh} \times 2^{+}\right)$at the expense of the hem $\left(W n t 5 a^{+}, W n t 3 a^{+}\right)$and choroid plexus $\left(B m p 7^{+}\right)$(Zhao et al., 1999; present study). The severe shortening of the cortical hem in $L h x 5$ mutants is likely to account for the decreased $p 21$ expression domain at the caudomedial telencephalon and for most of the reduction in C-R cell numbers. Indeed, fluorescent labeling of mutant embryos in a region that in wild-type embryos would correspond to the caudal cortical hem, yielded few migratory cells and those few stayed close of the injection point.

In wild-type mice, we confirmed that Ebf2, shown previously to be expressed in mature C-R cells (Chowdhury et al., 2010) of putative VP origin (Yamazaki et al., 2004; Hanashima et al., 2007), is expressed in reelin ${ }^{+}$cells in the neocortex and in the pOC and vCMTW regions at E12.5. Moreover, $L h x 1$, a gene predominantly expressed in reelin ${ }^{+}$and calretinin ${ }^{+}$cells in septal, pOC, and vCMTW regions but absent from the cortical hem at the peak of C-R cell generation, was also found in a fraction of neocortical reelin ${ }^{+}$cells. Hence, the observation in $L h x 5$ mutants of decreased $E b f 2$ and $L h x 1$ expression in the neocortical primor- 
dium and in the septal, pOC, and vCMTW regions suggests that $L h \times 5$ controls the differentiation of C-R cells from other potential sources in addition to the cortical hem. As in previous studies (Bielle et al., 2005; Yoshida et al., 2006; Tissir et al., 2009), the drastic reduction of C-R cells in the dorsal telencephalon of $\operatorname{Lh} \times 5$ mutants did not result in reeler-like phenotypes such as cortical layer inversion, suggesting that compensatory mechanisms ensure a minimum of C-R cells to accomplish their main functions.

In the mutant embryos, we found that the domain in the vCMTW region defined by expression of $L h x 1$, which was extended dorsally compared with control embryos, gave rise to cells expressing reelin, p73, Lhx1, and Ebf2 that migrate and cluster ectopically in the caudal telencephalon (see diagram in supplemental Fig. $4 D$, available at www.jneurosci.org as supplemental material). Their site of origin, however, appears to be a domain with properties that differ from those of the reelin-expressing domains found in this region in wild-type embryos; it expresses p21, a marker of early differentiated hemderived C-R cells as well as $L h x 1$, a gene expressed predominantly in the vCMTW region. Thus, ectopic cell migration in Lhx5 mutants could be related to altered intrinsic properties of specific reelin ${ }^{+}$cell subsets or, alternatively, to non-cellautonomous modifications in the caudal telencephalon related to the loss of cortical hem and choroid plexus territories. Small clusters $\left(\right.$ reelin ${ }^{+}, E_{b f 2}{ }^{+}$, and $p 73^{+}$) associated to the pOC were also found laterally with some variability in their location but their origin was not determined. At birth, aberrant cell clustering persisted caudally in olfactory cortical regions, and interestingly, cellular ectopias have also been reported in embryos carrying mutant alleles of $p 73$, Zic1-3, and Tbr1, also involved in C-R cell development (Hevner et al., 2001; Meyer et al., 2004; Inoue et al., 2008). Another medial telencephalic region in which migration may be altered in mutant embryos is the septal territory. At E11.5, there is a clear signal reduction only with the reelin probe. At E12.5, however, there appears to be a signal reduction with reelin, $p 73$, $p 21$, and, more dramatically, with the $L h x 1$ probe. Aberrant migration of reelin ${ }^{+}$cells from or to this region might cause the differences observed with the various markers at both stages.

Recent studies have uncovered the prospective olfactory cortex as a complex territory where heterogeneous cell populations born both at local and distant telencephalic locations converge (Tomioka et al., 2000; García-Moreno et al., 2008). In keeping with this, the reelin-expressing population found in this region appears to be heterogeneous as well containing C-R and other olfactory cells. Reelin-expressing cells in this region have been shown to contain VP and dorsal midline derivatives (Bielle et al., 2005; Imayoshi et al., 2008), and our studies in wild-type mice revealed that it also contains cells originating at a site in the
vCMTW region that reach the pOC by tangential migration. Hence, the reelin/Lhx5/Lhx1-expressing population in this region may also be a heterogeneous cell group with cell types from various sources. We found that, in the migrating population from the vCMTW region, most cells possess a phenotype similar to that of C-R cells, as they express reelin, calretinin, and Tbr1, lack calbindin expression, and are located in the outermost layer of the telencephalon. At least a fraction of reelin-expressing cells, however, remains in this region at E13.5 (data not shown) and thus appears to correspond to olfactory cell types rather than to $\mathrm{C}-\mathrm{R}$ cells. These cells could have a guidance role, as has been described for LOT cells (Tomioka et al., 2000), but additional investigation is required to determine their final location, identity, and function.

Previous studies have proposed that reelin ${ }^{+}$migratory cells are generated at various sites of the medial telencephalic wall in addition to $\mathrm{C}-\mathrm{R}$ cells from the cortical hem. These include the prospective choroid plexus (Imayoshi et al., 2008) and a broad region in the CMTW (Takiguchi-Hayashi et al., 2004). Another study proposed the thalamic eminence, a region rich in $p 73, \operatorname{Lh} \times 5$, and reelin expression as a source of C-R cells (Tissir et al., 2009; 
Abellan et al., 2010), but this remains to be confirmed. In our experiments in wild-type embryos, labeling was aimed at the ventricular surface of the caudomedial Lhx1/Lhx5 expression domain adjacent to the telencephalon-diencephalon border, and hence it is not likely to label migratory cells at the mantle zone of this region in transit from other regions. Other migratory populations potentially originating from adjacent caudal subdomains such as the caudal cortical hem, the prospective choroid plexus, or even the diencephalon, however, may follow this route to the olfactory region. A precise characterization of all reelin ${ }^{+}$populations that originate at or migrate through this region will lead to a better understanding of this developmentally complex region.

Our results indicate that the main effect of the deletion of $L h \times 5$ in C-R cell development is attributable to impaired dorsal midline development. Since we did not detect an increase in apoptotic cell death at E11.5 and E12.5 in mutant embryos in other regions of the telencephalon where $L h x 5$ is normally expressed (Zhao et al., 1999) (data not shown), this transcription factor is likely to be involved in the control of early cell differentiation in those regions rather than in proliferation. Consistent with this, Lhx $5 / 1$ have been implicated in the control of postmitotic differentiation of specific cellular subsets in the hippocampus, cerebellum, retina, and spinal cord (Zhao et al., 1999, 2007; Poché et al., 2007). Moreover, our data reveal that Lhx5 is also required for proper migration of a subset of reelin ${ }^{+}$cells. Overall, our findings show that $L h \times 5$ plays important roles in the development of C-R cells and of reelin ${ }^{+}$olfactory cells and that $L h x 1$ is expressed in particular subsets of these cells from early developmental stages. As transcription factors, $L h \times 5 / 1$ must exert their function through the regulation of downstream target genes. Given the potential of LIM protein-protein interactions, intricate regulatory mechanisms between members of LIM-HD factors in the telencephalon are thus expected during the development of early telencephalic populations including C-R cells.

\section{References}

Abellan A, Menuet A, Dehay C, Medina L, Retaux S (2010) Differential expression of LIM-homeodomain factors in Cajal-Retzius cells of primates, rodents, and birds. Cereb Cortex 20:1788-1798.

Bielle F, Griveau A, Narboux-Nême N, Vigneau S, Sigrist M, Arber S, Wassef M, Pierani A (2005) Multiple origins of Cajal-Retzius cells at the borders of the developing pallium. Nat Neurosci 8:1002-1012.

Chowdhury TG, Jimenez JC, Bomar JM, Cruz-Martin A, Cantle JP, PorteraCailliau C (2010) Fate of Cajal-Retzius neurons in the postnatal mouse neocortex. Front Neuroanat 4:10.

D'Arcangelo G, Nakajima K, Miyata T, Ogawa M, Mikoshiba K, Curran T (1997) Reelin is a secreted glycoprotein recognized by the CR-50 monoclonal antibody. J Neurosci 17:23-31.

de Carlos JA, López-Mascaraque L, Valverde F (1996) Dynamics of cell migration from the lateral ganglionic eminence in the rat. J Neurosci 16:6146-6156.

Fujii T, Pichel JG, Taira M, Toyama R, Dawid IB, Westphal H (1994) Expression patterns of the murine LIM class homeobox gene lim1 in the developing brain and excretory system. Dev Dyn 199:73-83.

García-Moreno F, López-Mascaraque L, De Carlos JA (2007) Origins and migratory routes of murine Cajal-Retzius cells. J Comp Neurol 500:419-432.

García-Moreno F, López-Mascaraque L, de Carlos JA (2008) Early telencephalic migration topographically converging in the olfactory cortex. Cereb Cortex 18:1239-1252.

Gong S, Zheng C, Doughty ML, Losos K, Didkovsky N, Schambra UB, Nowak NJ, Joyner A, Leblanc G, Hatten ME, Heintz N (2003) A gene expression atlas of the central nervous system based on bacterial artificial chromosomes. Nature 425:917-925.

Hanashima C, Li SC, Shen L, Lai E, Fishell G (2004) Foxg1 suppresses early cortical cell fate. Science 303:56-59.

Hanashima C, Fernandes M, Hebert JM, Fishell G (2007) The role of Foxg1 and dorsal midline signaling in the generation of Cajal-Retzius subtypes. J Neurosci 27:11103-11111.

Hevner RF, Shi L, Justice N, Hsueh Y, Sheng M, Smiga S, Bulfone A, Goffinet AM, Campagnoni AT, Rubenstein JL (2001) Tbr1 regulates differentiation of the preplate and layer 6. Neuron 29:353-366.

Hevner RF, Neogi T, Englund C, Daza RA, Fink A (2003) Cajal-Retzius cells in the mouse: transcription factors, neurotransmitters, and birthdays suggest a pallial origin. Brain Res Dev Brain Res 141:39-53.

Imayoshi I, Shimogori T, Ohtsuka T, Kageyama R (2008) Hes genes and neurogenin regulate non-neural versus neural fate specification in the dorsal telencephalic midline. Development 135:2531-2541.

Inoue T, Ogawa M, Mikoshiba K, Aruga J (2008) Zic deficiency in the cortical marginal zone and meninges results in cortical lamination defects resembling those in type II lissencephaly. J Neurosci 28:4712-4725.

Kania A, Johnson RL, Jessell TM (2000) Coordinate roles for LIM homeobox genes in directing the dorsoventral trajectory of motor axons in the vertebrate limb. Cell 102:161-173.

Kaufman M (1992) The atlas of mouse development. London: Academic.

Mallamaci A, Mercurio S, Muzio L, Cecchi C, Pardini CL, Gruss P, Boncinelli E (2000) The lack of Emx2 causes impairment of Reelin signaling and defects of neuronal migration in the developing cerebral cortex. J Neurosci 20:1109-1118.

Mangale VS, Hirokawa KE, Satyaki PR, Gokulchandran N, Chikbire S, Subramanian L, Shetty AS, Martynoga B, Paul J, Mai MV, Li Y, Flanagan LA, Tole S, Monuki ES (2008) Lhx2 selector activity specifies cortical identity and suppresses hippocampal organizer fate. Science 319:304-309.

Meyer G, Soria JM, Martínez-Galán JR, Martín-Clemente B, Fairén A (1998) Different origins and developmental histories of transient neurons in the marginal zone of the fetal and neonatal rat cortex. J Comp Neurol 397:493-518.

Meyer G, Perez-Garcia CG, Abraham H, Caput D (2002) Expression of p73 and Reelin in the developing human cortex. J Neurosci 22:4973-4986.

Meyer G, Cabrera Socorro A, Perez Garcia CG, Martinez Millan L, Walker N, Caput D (2004) Developmental roles of p73 in Cajal-Retzius cells and cortical patterning. J Neurosci 24:9878-9887.

Muzio L, Mallamaci A (2003) Emx1, emx2 and pax6 in specification, regionalization and arealization of the cerebral cortex. Cereb Cortex 13:641-647.

Muzio L, Mallamaci A (2005) Foxg1 confines Cajal-Retzius neuronogenesis and hippocampal morphogenesis to the dorsomedial pallium. J Neurosci 25:4435-4441.

Parr BA, Shea MJ, Vassileva G, McMahon AP (1993) Mouse Wnt genes exhibit discrete domains of expression in the early embryonic CNS and limb buds. Development 119:247-261.

Poché RA, Kwan KM, Raven MA, Furuta Y, Reese BE, Behringer RR (2007) Lim1 is essential for the correct laminar positioning of retinal horizontal cells. J Neurosci 27:14099-14107.

Ramírez-Amaya V, Vazdarjanova A, Mikhael D, Rosi S, Worley PF, Barnes CA (2005) Spatial exploration-induced Arc mRNA and protein expression: evidence for selective, network-specific reactivation. J Neurosci 25:1761-1768.

Shen Q, Wang Y, Dimos JT, Fasano CA, Phoenix TN, Lemischka IR, Ivanova NB, Stifani S, Morrisey EE, Temple S (2006) The timing of cortical neurogenesis is encoded within lineages of individual progenitor cells. Nat Neurosci 9:743-751.

Sheng HZ, Bertuzzi S, Chiang C, Shawlot W, Taira M, Dawid I, Westphal H (1997) Expression of murine Lhx5 suggests a role in specifying the forebrain. Dev Dyn 208:266-277.

Siegenthaler JA, Miller MW (2008) Generation of Cajal-Retzius neurons in mouse forebrain is regulated by transforming growth factor beta-Fox signaling pathways. Dev Biol 313:35-46.

Soriano E, Del Río JA (2005) The cells of Cajal-Retzius: still a mystery one century after. Neuron 46:389-394.

Stoykova A, Hatano O, Gruss P, Götz M (2003) Increase in reelin-positive cells in the marginal zone of Pax6 mutant mouse cortex. Cereb Cortex 13:560-571.

Takiguchi-Hayashi K, Sekiguchi M, Ashigaki S, Takamatsu M, Hasegawa H, Suzuki-Migishima R, Yokoyama M, Nakanishi S, Tanabe Y (2004) Generation of reelin-positive marginal zone cells from the caudomedial wall of telencephalic vesicles. J Neurosci 24:2286-2295. 
Tissir F, Ravni A, Achouri Y, Riethmacher D, Meyer G, Goffinet AM (2009) DeltaNp73 regulates neuronal survival in vivo. Proc Natl Acad Sci U S A 106:16871-16876.

Tomioka N, Osumi N, Sato Y, Inoue T, Nakamura S, Fujisawa H, Hirata T (2000) Neocortical origin and tangential migration of guidepost neurons in the lateral olfactory tract. J Neurosci 20:5802-5812.

Tsuchida T, Ensini M, Morton SB, Baldassare M, Edlund T, Jessell TM, Pfaff SL (1994) Topographic organization of embryonic motor neurons defined by expression of LIM homeobox genes. Cell 79:957-970.

Varela-Echavarría A, Pfaff SL, Guthrie S (1996) Differential expression of LIM homeobox genes among motor neuron subpopulations in the developing chick brain stem. Mol Cell Neurosci 8:242-257.

Yamazaki H, Sekiguchi M, Takamatsu M, Tanabe Y, Nakanishi S (2004) Distinct ontogenic and regional expressions of newly identified CajalRetzius cell-specific genes during neocorticogenesis. Proc Natl Acad Sci U S A 101:14509-14514.

Yoshida M, Assimacopoulos S, Jones KR, Grove EA (2006) Massive loss of
Cajal-Retzius cells does not disrupt neocortical layer order. Development 133:537-545.

Zhao Y, Sheng HZ, Amini R, Grinberg A, Lee E, Huang S, Taira M, Westphal H (1999) Control of hippocampal morphogenesis and neuronal differentiation by the LIM homeobox gene Lhx5. Science 284:1155-1158.

Zhao Y, Kwan KM, Mailloux CM, Lee WK, Grinberg A, Wurst W, Behringer RR, Westphal H (2007) LIM-homeodomain proteins Lhx1 and Lhx5, and their cofactor Ldb1, control Purkinje cell differentiation in the developing cerebellum. Proc Natl Acad Sci U S A 104:13182-13186.

Zimmer C, Tiveron MC, Bodmer R, Cremer H (2004) Dynamics of Cux2 expression suggests that an early pool of SVZ precursors is fated to become upper cortical layer neurons. Cereb Cortex 14:1408-1420.

Zimmer C, Lee J, Griveau A, Arber S, Pierani A, Garel S, Guillemot F (2010) Role of Fgf8 signalling in the specification of rostral Cajal-Retzius cells. Development 137:293-302. 